\title{
Research about the influencing factors of Inter-organizational knowledge transferring based on alliance environment
}

\author{
YueFeng Zhou ${ }^{1,}$, , XueQing Jing ${ }^{1, b}$ \\ ${ }^{1}$ College of Economics and Management, Dalian University, Dalian, Liaoning, 116622, China \\ azhouyf66@263.net, bajingxueqing@163.com
}

\begin{abstract}
Keywords: Alliance environment; Inter-organizational knowledge transferring; Trustful level;
\end{abstract} Potential difference

\begin{abstract}
In order to study the effecting facts of inter-organizational knowledge transferring, it mainly analyses from potential difference and trustful level, and builds up the model which describes the potential difference and trustful level have effect on the average level and transferring rate of the alliance. It simulates the model by the MATLAB system, and the result indicates the knowledge potential difference is enough big to promote the knowledge transferring and the average level of enterprise alliance; the trustful level is enough strong to increase the knowledge transferring, and it has positive effect on the average level of enterprise alliance.
\end{abstract}

\section{Introduction}

With the advent of knowledge economy, knowledge and information has gradually become the most important resource, under the environment of knowledge economy, knowledge is considered to be the enterprise's most valuable resources, and the use of appropriate knowledge can significantly enhance the enterprise the competitive ability. The existence of the knowledge alliance provides an efficient form of organization knowledge study; for many are not easy to transfer knowledge provides the transfer platform. Generally speaking, Knowledge alliance refers to the enterprise and between enterprises or between enterprises and other institutions to build core competence, for the purpose, to create new knowledge, or knowledge learning and form a coalition. Participants of knowledge alliance are mainly devoted to study or to create new knowledge. In 1994, Nonaka [1] thought of knowledge management in the area of one of the most important one is the different between knowledge unit transfer researches, and argues that knowledge transfer is the transfer of knowledge between different units. In 1996, Szulanski [2] think that knowledge transfer will be defined as a process, this process, complex and ambiguous rules in the new environment of constant innovation and is being maintained. In 1998, Davenport and Prusak [3] think that knowledge transfer will be expressed as the following formula, knowledge transfer=the degree of knowledge communicate+ receiving the degree of knowledge. Knowledge transfer need to first pass by the owner to potential recipients, and then be absorbed by the recipients. In 2000, Dixon [4] think that Knowledge transfer is will exist in a certain part of organization knowledge, applied to another part within the organization, and organization members need through a variety of tools to realize knowledge sharing. On the basis of inheriting predecessors' research, this article mainly from the perspectives of enterprise alliance environmental levels are discussed under the process of knowledge transfer mechanism has carried on the thorough discussion, to improve the enterprise's knowledge management, improve the competitive position of enterprises has important theoretical significance and practical value.

\section{Basic principle of Inter-organizational knowledge transferring}

Knowledge potential difference. In enterprise alliance, the development of every member companies and the living environment is different [5-6], every enterprise has their own unique knowledge resources advantage, their resources for knowledge learning and access path is different also, therefore, is bound to form a knowledge potential difference within the alliance, which is what we usually call also the knowledge of the differences. Knowledge differences are the important 
factors that affect knowledge transfer efficiency, generally speaking, the alliance between enterprises in knowledge, the smaller the gap of knowledge level, so, new knowledge, the less the amount of information in the process of knowledge transfer. Knowledge flows in the league organizations is to put the high potential of the organization knowledge to potential low organizational knowledge transfer process. Directional fully illustrates the knowledge transfer process between knowledge in the alliance organization distribution is uneven, namely knowledge there is a potential difference between each group node. So this paper argues that the knowledge potential difference is one of the driving forces for the organization of knowledge transfer; This article will knowledge potential difference as the sender and the receiver have knowledge stock or knowledge gap. When knowledge potential exists asymmetry, in the low potential of the organization will seek knowledge to make up for the lack of knowledge of potential difference. This eventually led to the learning process knowledge transfer between organizations.

The level of trust. Establish strategic cooperative relations between enterprises on the premise that business organizations have common goals and mutual trust among business organizations. Union organizations trust mechanism is effective knowledge transfer between the foundations, especially tacit knowledge flow process, Trust has the perceptual characteristic and rational characteristic, but also has social attribute. According to the different properties of trust, from the perspective of psychology can be divided into two categories, rational trust and perceptual trust; from the perspective of social property trust and trust can be divided into personal and organizational trust. In enterprise alliance, the relationship between the enterprise and the enterprise is a long-term, is based on common goal oriented strategic cooperative relations, but also based on understanding and cooperation on the basis of before, so the trust between enterprises more and more performance for the perceptual rational trust and trust. So this paper argues that in the process of knowledge transfer between organizational trusts plays a significant impact. The sender has the high degree of trust between enterprises make knowledge transfer knowledge will, also can let the knowledge recipient believes that the reliability and value of knowledge.

\section{Numerical Model}

The paper simulates the inter-organizational knowledge transferring process within alliance based on MATLAB numerical software. The model effectively analyzes the average level and transferring rate of the enterprise alliance by changing the factors of the inter-organizational knowledge transferring.

Based on strategic alliance knowledge flow characteristics, finally established the alliance of two indicators to reflect the whole process of knowledge transfer: Union overall average level of knowledge and Alliance overall knowledge transfer rate.

Union overall average level of knowledge. Union body junction point in $T=t+1$ knowledge can be expressed as Eq.1

$$
H_{i, t+1}=H_{i, t}+\Delta H_{i, t+1}
$$

This time in $t \rightarrow t+1$, the amount of increase in knowledge can be expressed as Eq.2.

$$
\Delta H_{i, t+1}=\sum_{i, j \in G_{i}} a\left(H_{i, t}\right) b\left(S_{j, t}\right) \gamma\left(S_{j, t}-H_{i, t}\right) e_{i j}+\gamma H_{i, t} \quad\left\{\begin{array}{c}
0 \leq \gamma \leq 1 \\
0 \leq b \leq 1 \\
0 \leq \gamma H_{i, t} \leq S_{t} \\
a(0)=0
\end{array}\right.
$$

So, when the time $T=\mathrm{t}$, the overall knowledge of the Union average level can be expressed as Eq.3.

$$
\overline{H_{t}}=\frac{1}{N} \sum_{i \in G}\left[\theta N S_{i, t}+(1-\theta) N H_{i, t}\right]
$$


Where $H_{i, t}$ is knowledge of the sender node potential difference, $a\left(H_{i, t}\right)$ is knowledge of the knowledge absorptive capacity, $b\left(S_{j, t}\right)$ is knowledge of the sender sends the ability, $\gamma$ is nodes $i$ in knowledge innovation ability, $N$ is node number, $G$ is established by a number of small and medium enterprises unions, $\overline{H_{t}}$ is union overall average of knowledge.

Alliance overall knowledge transfer rate. Union's overall knowledge transfer rate can be defined as the mean of the union all nodes per unit time knowledge transfer incremental. The union moment of transfer rate can be expressed as Eq.4.

$$
\bar{V}_{t \rightarrow t+1}=\frac{1}{N} \sum_{i \in G} \Delta H_{i, t}
$$

Where $\bar{V}_{t \rightarrow t+1}$ is alliance overall knowledge transfer rate, $N$ is node number.

\section{The simulation results}

It analyzes the influence of knowledge transferring from Potential difference, Assume $b=0.4$, $\gamma=0.2, W=0.5$, High potential nodes and low potential of initial potential is the same numerical value, that is $S+H=10$, different values of $S$ and $H$ create potential difference of different knowledge, to analysis different knowledge potential difference effect on the performance of knowledge transfer. Fig.1 presents alliance knowledge average was influenced different potential difference. From Fig.1 can get the greater the potential difference of knowledge, knowledge recipients' willingness to learn that knowledge more intense, and more opportunities for communication between both sides, the more knowledge the recipient will absorb external knowledge to improve their knowledge potential, and ultimately makes the larger union average level of knowledge. Fig.2 presents alliance knowledge transfer rate was influenced different potential difference. From Fig.2 can get Knowledge potential difference larger unit time gained more knowledge of knowledge, namely knowledge transfer rate increases.

It analyzes the influence of knowledge transferring from degree of trust. Assume $a=0.1, b=0.4$ $\gamma=0.2$, union overall average trust takes different values, the union as a whole the average level of knowledge and transfer rate change trend. Fig.3 presents alliance knowledge average was influenced different degree of trust. From Fig.3 can get the level of trust between nodes on the union average level of knowledge have important implication. The level of trust between nodes is higher; the overall average level of knowledge alliance will also greatly improve. Fig.4 presents alliance knowledge transfer rate was influenced different degree of trust. From Fig. 4 can get the level of trust between

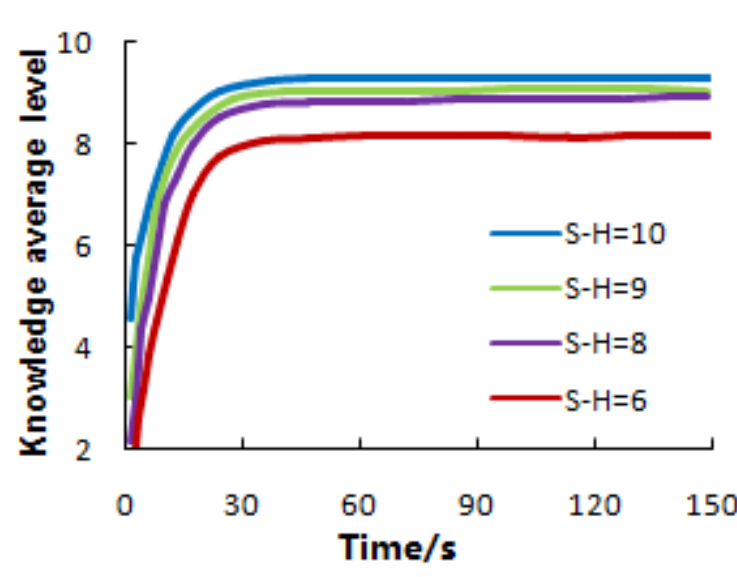

Fig.1. Potential difference-average level curve

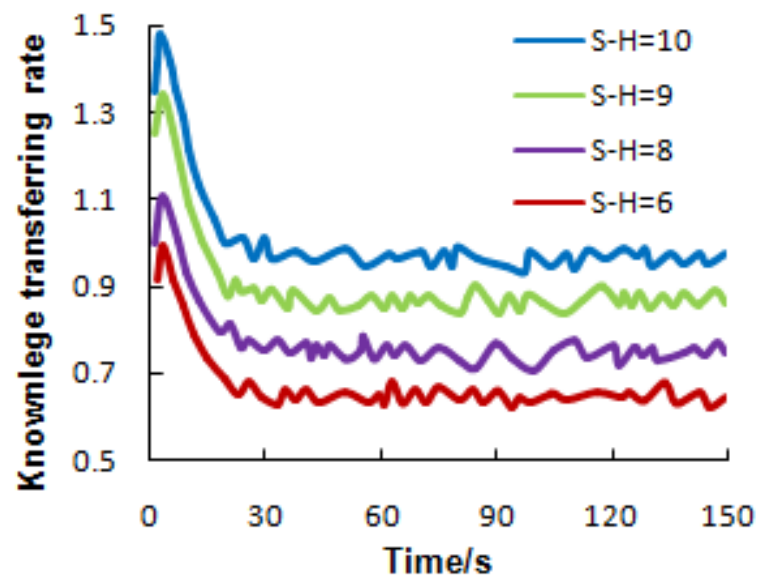

Fig.2. Potential difference-transferring rate curve 


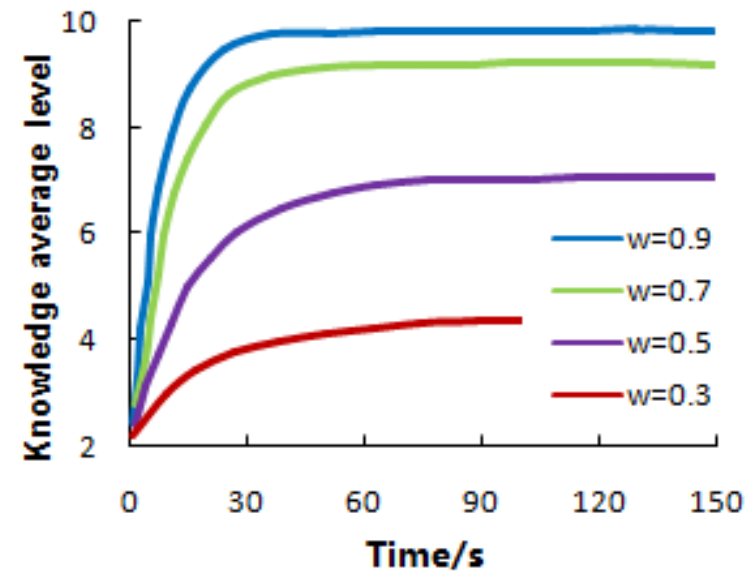

Fig.3. Trustful level-knowledge average level curve

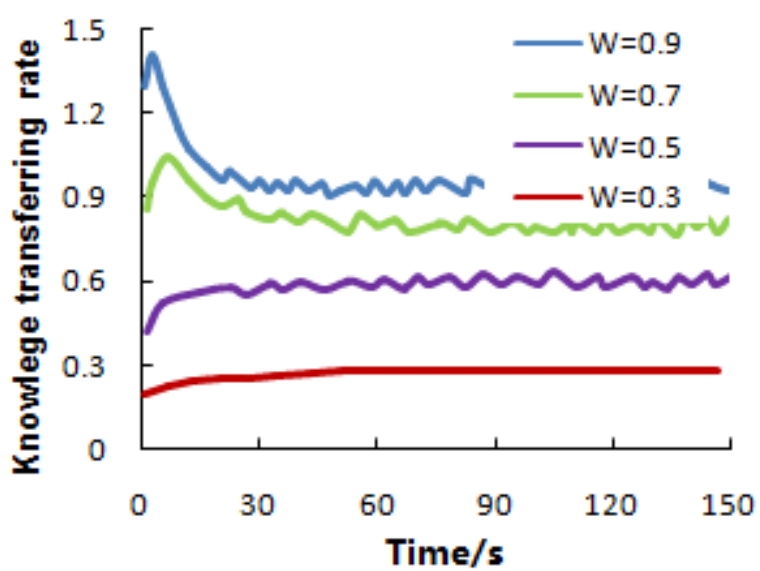

Fig.4. Trustful level-transferring rate curve

nodes is higher, the transfer of knowledge between organizations willingness higher sides knowledge transfer in unit time the quality and quantity, the more that is within the knowledge of the whole union during the transfer rate is higher.

\section{Summary}

Inside the enterprise alliance, the influence factors of knowledge transfer is very complicated in the process of inter-organizational learning. This paper from two aspects of knowledge potential difference and trust it to inter-organizational knowledge transfer within the alliance effect and the impact of rate, build up the knowledge potential difference between the groups and the trust degree to the overall level of knowledge alliance and metastasis rate of the model, based on MATLAB software for simulation of this model, through different knowledge potential difference and the trust degree of parameters to analyze the knowledge transfer among organizations in an alliance performance, the result indicates the knowledge potential difference is enough big to promote the knowledge transferring and the average level of enterprise alliance; the trustful level is enough strong to increase the knowledge transferring, and it has positive effect on the average level of enterprise alliance.

\section{References}

[1]Nonaka I. A Dynamic Theory of Organizational Knowledge Creation.organization Science, 1994, 5: 4-37

[2] Szulanski G. Exploring internal stickiness: Impediments to the transfer of best practice within the firm. Strategic Management Journal, 1996, 17:27-44

[3] Davenport, T.H., \& Prusak, L. (1998). Working knowledge: how organisations manage what they know. Boston, MA: Harvard Business School Press

[4]Dixon, N.M. Common knowledge: How companies thrive by sharing what they know. Boston: Havard Business School Press, 2000

[5]F.C. Tang, Y. M. X, Knowledge Transfer and dynamic behavior patterns of network organization. Systems Engineering-theory \& Practice,volume, pp.83-89, 2006.

[6]Li wei an, Organization complexity: motivation, control and utilization Organization complexity: motivation, control and utilization. Tianjin Social Sciences,volume5:59 - 63, 2005 